\title{
Modelling the Relationship between Sludge Filtration Resistance and Capillary Suction Time
}

\author{
L. W. Arimiearii ${ }^{*}$, J. O. Ademiluyi ${ }^{2}$ \\ ${ }^{1}$ Department of Civil Engineering, Rivers State University, Port Harcourt, Nigeria \\ ${ }^{2}$ Department of Civil Engineering, University of Nigeria, Nsukka, Nigeria \\ Email: *luvi4real@yahoo.com, professorademiluyi@yahoo.com
}

How to cite this paper: Arimieari, L.W and Ademiluyi, J.O. (2018) Modelling the Relationship between Sludge Filtration Resistance and Capillary Suction Time. Journal of Environmental Protection, 9, 91-99. https://doi.org/10.4236/jep.2018.92007

Received: December 5, 2017

Accepted: February 20, 2018

Published: February 23, 2018

Copyright (c) 2018 by authors and Scientific Research Publishing Inc. This work is licensed under the Creative Commons Attribution International License (CC BY 4.0).

http://creativecommons.org/licenses/by/4.0/

\section{c) (i) Open Access}

\begin{abstract}
This study modeled the relationship between Sludge Filtration Resistance (SFR) and Capillary Suction Time (CST) using the data generated from different concentrations of $\mathrm{CaCl}_{2}$ for SFR and CST empirically using the Equation proposed by Christensen et al. (1993). The main purpose of conducting CST and SRF tests at wastewater treatment plants is to save operating costs by evaluating the optimal dose of the sludge conditioner, known as the dose of coagulant that yields the minimal capillary suction time or resistance to filtration. In order to establish a relationship between the SFR with CST, there is a relatively good correlation between CST and SFR. The results showed that the values of CST decreased with increasing $\mathrm{CaCl}_{2}$ concentration, and a good dewaterability could be obtained at the $\mathrm{CaCl}_{2}$ dosage of $18 \mathrm{~g}$ with the corresponding CST of $5.52 \mathrm{~s}$ for $20 \mathrm{~mm}$ internal cylinder and $30.84 \mathrm{~s}$ for $14.5 \mathrm{~mm}$ internal cylinder. The results of SFR tests shown decreased with an increase in $\mathrm{CaCl}_{2}$ dosage. The optimal $\mathrm{CaCl}_{2}$ dosage was $18 \mathrm{~g}$ and the corresponding SFR was $2.65 \times 10^{8} \mathrm{~N} \cdot \mathrm{s} / \mathrm{m}^{5}$. The results of this study for CST recommend larger diameter cylinder to be used to test heavy sludge because the larger cylinder significantly reduces the variability and the time taken to conduct the CST tests.
\end{abstract}

\section{Keywords}

Sludge Filterability Measures, Conditioning Characteristics

\section{Introduction}

There is a relationship between the sludge resistance filtration (SRF) and the rate at which the water travels between the electrodes of the capillary suction time 
(CST) device for a wide range of different types of sludge [1]. Filtration as a mechanical method which is commonly applied for solid-liquid separation [2] while improving sludge cake filterability is one of several ways to enhance biosludge dewaterability [3]. The standard CST test was first developed by [4]. The components include an open stainless steel cylindrical column or funnel with a Whatman filter paper at the base, multiple electrodes, which serve to sense the movement of filtrate across the paper, and a timer. A sample of sludge is poured into the column, and the filtrate is extracted by capillary suction through the paper, so that a cake is formed on the filter. A better approach to model the filterability of sludge filtration systems was proposed based on adapting models originally defined to describe the fouling of membranes, and corrected for the rapid increase in the slope of $t / \mathrm{V}$ versus $\mathrm{V}$ when the filter becomes blocked with particles and the flow rate of water slows down [5]. The importance of different floc sizes and structures to explain the variability in the dewaterability of sludge using CST tests was highlighted [1] [6]. Capillary suction time (CST) represents the filterability and has many advantages, such as easy operation, it is far from realistic since no pressure is applied and the easiness of removing moisture from slurry and sludge in numerous environmental and industrial applications [7]. It is clear from both theoretical and practical viewpoints, that one of the major problems of the standard CST test, particularly when testing heavy sludges, is that suspended particles accumulate on top of the paper by sedimentation. This may lead to an overestimation of the cake resistance, since the primary theory of the CST test does not take the effects of sedimentation into account [8] [9]. A flow of bubbles could be introduced into the CSA apparatus to reduce sedimentation [10]. A constant current, induced by a stirrer within the sludge chamber, may also reduce or prevent sedimentation, thereby improving the results of CST tests [1]. A dilution method that reduces the salinity is known to affect the SRF and consequently the CST [11]. The reason for using four different models was that the slope of a regression line varies in magnitude depending on whether or not intercepts are fitted, and whether or not the $\mathrm{X}$ and/or $\mathrm{Y}$ variables have been transformed [12].

The importance of different floc sizes and structures to explain the variability in the dewaterability of sludge using CST tests was highlighted [1] [6]. Sludge filterability, which is a known function of SRF, was shown using mathematical modelling to be estimable from CST values [13]. The reason for using four different models was suggested that the slope of a regression line varies in magnitude depending on whether or not intercepts are fitted, and whether or not the $\mathrm{X}$ and/or Y variables have been transformed [12]. The results of the CST and SRF tests are correlated meaning that the SRF value can be predicted from the CST test results [14]. It was shown that in the case of electrodewatering, the achievable dewatering results were less dependent on the polyelectrolyte features or sludge composition, and overall better. This suggests that electrodewatering is not only very well suited to increase the cake dry matter content, but will also guarantee a good dewatering performance, regardless of sludge and conditioning 
history [15]. Indicators such as sludge particle size distribution; CST, SRF and supernatant filterability were monitored that are valuable tools to compare the sludge filterability at different reactors under standardized conditions [16] [17]. Various studies have tried to investigate and model the relationship between CST and SRF with the purpose of obtaining the averaged specific resistance of filtration cake from the data generated by CST tests. A method was proposed that allowed SRF to be calculated without the liquid invasion volume measurement using capillary suction apparatus [18]. A similar work by [19] resented a newly developed model of CST apparatus able to determine specific cake resistances of both unflocculated and flocculated sludges. The capillary suction time (CST) and the specific resistance to filtration (SRF) tests are both commonly used to estimate sludge dewaterability. Both tests are known to be empirically related but the SRF test is more difficult to execute, time consuming, and expensive than the CST test, and no specific device to measure SRF is available [5] [20] [21] and differences in the apparatus and procedures used, e.g., the filter medium and the vacuum applied, have been found to cause variability in the results of SRF tests reported by different workers [22] [23]. The most common application of CST and SRF tests, however, is to support industrial wastewater treatment processes. CST and SRF tests are applied routinely as support operations, to determine the capacity of sludge to be dewatered, and to select the most appropriate mechanical drying processes [1] [5]. CST and SRF tests are also applied to support the choice of a conditioning process to improve sludge dewaterability [24].

This study is aimed at contributing towards the development of improved measures of filterability and relates the results of SRF tests to the results of CST tests in order to model the relationship between sludge filtration resistance and capillary suction time.

\section{Materials and Method}

\section{Capillary Suction Time (CST) Apparatus}

There are different ways to characterize the filterability of sludges. Compactibility as a new method to investigate the dewaterability of biological sludges and the results of the study revealed that the compactibility, in terms of solid content of compacted sludge, should be measured together with SRF and CST to find the most proper dewatering method for the sludges [25]. The SRF can be used for measurement of the relative dewatering quality of sludges from various wastewater treatment plants, provided the text is conducted in a consistent manner [22]. Capillary Suction Time (CST) and Specific Resistance to Filtration (SRF) measurements for the organic activated sludge conditioned with fly ash and polymer [26]. CST was reported as the dependent (predicted) variable and SRF, sludge solid content, and sludge viscosity as the independent (predictor) variables) [27]. A relationship was proposed between the CST and the SRF settings based on SRF theory with a moderate positive correlation between log CST values and log 
values of the filtrate viscosity and SRF based on theoretical approach [28]. A relatively good correlation was reported between normalized CST and SRF $\left(\mathrm{R}^{2}=\right.$ 0.9450) and concluded that it is not necessary to use both CST and SRF at the same time to estimate the sludge dewaterability [29]. The normalized CST is feasible because of its affordability, simple equipment, and measurement procedure. There is a relationship between the capillary suction time and specific resistance to filtration [27]:

$$
\mathrm{CST}=C_{1} \times \mathrm{SRF} \times \mu_{f} \times w+C_{2} \times \mu_{f}
$$

where $C_{1}$ and $C_{2}$ are coefficients related to CST, $\mu_{f}$ is the viscosity of the filtrate and $\mathrm{w}$ is the solid content in unit volume of filtrate.

Standard CST apparatus was not available; hence the procedure described below was followed to fabricate the apparatus used for this study from the work done by [30].

\section{Plate Fabrication}

1) Two Perspex plates of sizes $150 \mathrm{~mm} \times 200 \mathrm{~mm} \times 5 \mathrm{~mm}$ were cut for the upper and lower plates respectively.

2) $3 \mathrm{~mm}$ diameter holes were drilled at the four edges to pass the clamping bolts.

3) Centre of the upper plate was located.

4) Using a pair of divider and with the point located in 3 above as reference point circle equal in diameter to the external diameter of the test cylinder was drawn on the upper plate.

5) Concentric circles were drawn round the first circle with the same reference point used in 4 above by increasing the diameter by $10 \mathrm{~mm}$ respectively until the plate surface is covered in order to measure the distance of the wet front advances.

6) A hole was drilled on the upper plate with a help of a drilling machine and with the point located in 3 above as centre.

7) Using a drilling machine the diameter of the hole in 6 above was increased to the external diameter of the test cylinder so that it can be passed to rest directly on the filter paper.

8) The same procedures from 3 to 7 were followed to make upper plates for the different test cylinders used for the study. The CST experimental setup is shown below (Plate 1).

\section{Cylinder Fabrication}

Two surgical syringes of internal and external diameters $(14.5 \mathrm{~mm}, 15.1 \mathrm{~mm})$ and $(20 \mathrm{~mm}, 21.1 \mathrm{~mm})$ were used for fabrication of the test cylinders. The closed end of the cylinder was cut off to make cylinder open at both ends.

\section{Capillary Suction Time Paper}

Whatman 1: Cat No 1001 - 125 was used for the CST test with a diameter of $12.5 \mathrm{~cm}$.

\section{Synthetic Sludge Sample}

Calcium chloride $\left(\mathrm{CaCl}_{2}\right)$ at various concentrations ranging from $10-18 \mathrm{~g}$ 

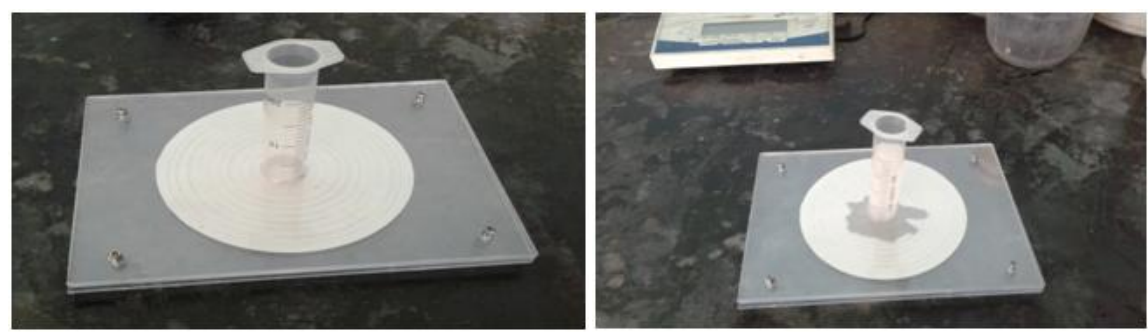

Plate 1. CST experimental setup (left) and CST experimental setup during filtration (right).

was used as a conditioner and mixed with $2 \mathrm{~g}$ of Borax, $2 \mathrm{~g}$ of Polyanionic Cellulose (PAC) and Carboxyl Methyl Cellulose (CMC) before filtration. The components were dissolved in a $320 \mathrm{ml}$ of distilled water.

\section{Data Reading System}

Due to unavailability of computerized data acquisition system, a stop watch was used to take the readings as the filtrate moved across the filter paper and timing started when the wet front of the filtrate reached the starting point from the cylinder centre.

\section{Results and Discussion}

\section{Relationship between SFR with CST}

The results of CST test produced from the time required for the wet front to reach each of the ten concentric circles were regressed on the distance between the ten concentric circles shown in Figure $1 \&$ Figure 2 for $20 \mathrm{~mm}$ and $14.5 \mathrm{~mm}$ internal cylinders.

In order to establish a relationship between SFR with CST, data generated from different concentrations of $\mathrm{CaCl}_{2}$ at the first filtrate were used for SFR and CST for the first concentric circle to be in line with the range of $\mathrm{CaCl}_{2}$ using the Equation proposed by [27] where they showed that there is a relationship between the capillary suction time and specific resistance to filtration. The equation is given below:

$$
\mathrm{CST}=C_{1} \times \mathrm{SRF} \times \mu_{f} \times w+C_{2} \times \mu_{f}
$$

where $C_{1}$ and $C_{2}$ are coefficients related to CST, $\mu_{f}$ is the viscosity of the filtrate and $\mathrm{w}$ is the solid content in unit volume of filtrate.

Comparing this to the Equation of a straight line

$$
Y=m x+c \text {. }
$$

For a graph of CST against SFR:

From the graph

$$
\begin{gathered}
\text { Slope }=c_{1} \times w \times \mu_{f} \\
c_{1}=\frac{\text { Slope }}{w \times \mu_{f}} \\
c_{1}=\frac{15.876}{w \times \mu_{f}}=\frac{15.876}{6.02 \times 0.01726}=152.793
\end{gathered}
$$




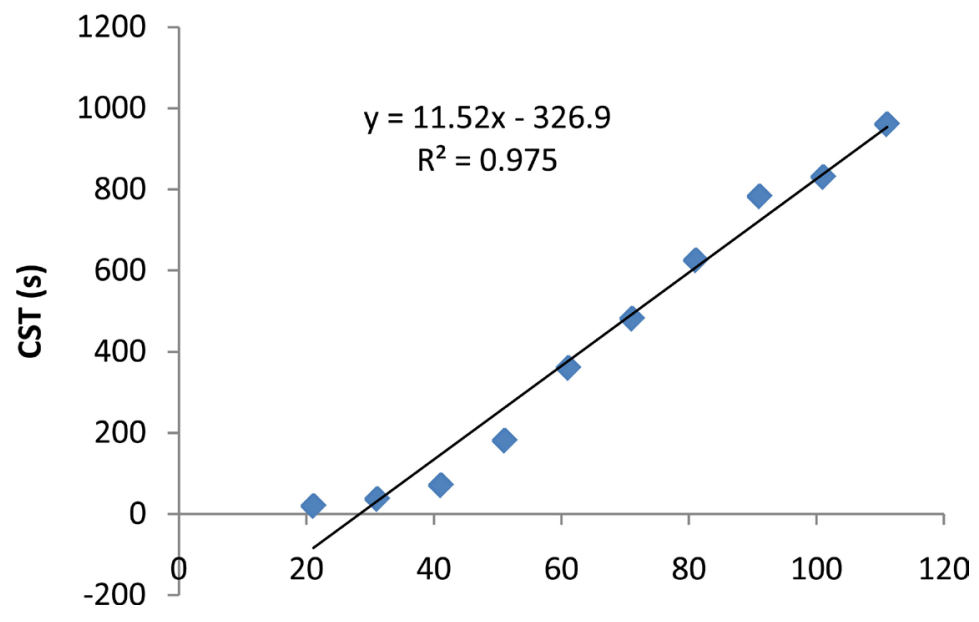

Figure 1. Plot of CST against the distance between external diameters for $20 \mathrm{~mm}$ using 10 $\mathrm{g}$ of $\mathrm{CaCl}_{2}$.

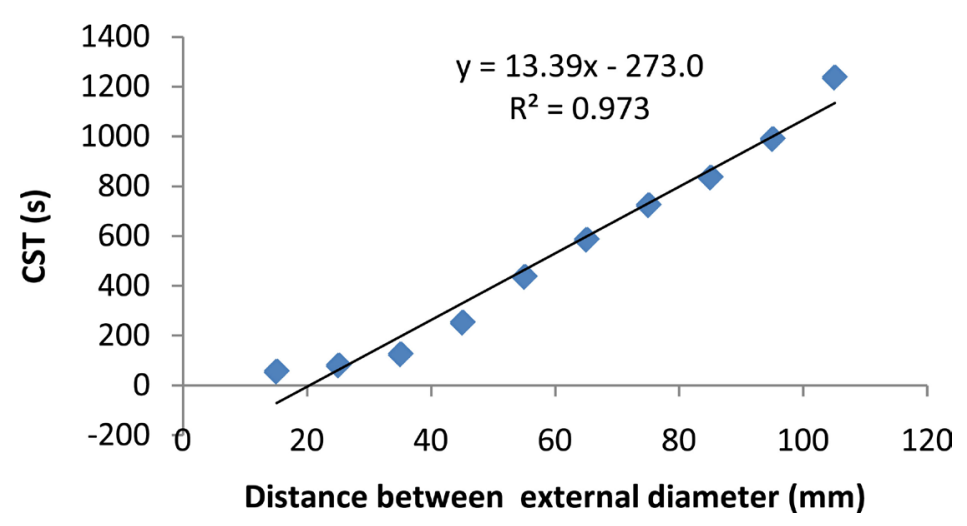

Figure 2. Plot of CST against the distance between external diameters for $14.5 \mathrm{~mm}$ using $10 \mathrm{~g}$ of $\mathrm{CaCl}_{2}$.

$$
\begin{gathered}
\text { Intercept }=c_{2} \times \mu_{f} \\
c_{2}=\frac{\text { Intercept }}{\mu_{f}}=\frac{-37.129}{0.01726}=-2.1516 .
\end{gathered}
$$

The data used in Section 3. Results and Discussion show the relationship between CST and SFR based on the range of coagulant $\left(\mathrm{CaCl}_{2}\right)$ for $10 \mathrm{~g}, 12 \mathrm{~g}, 14 \mathrm{~g}$, $16 \mathrm{~g}$ and $18 \mathrm{~g}$ in order to evaluate the optimal dose of the sludge conditioner, which is the dose of coagulant that produces the minimal CST and SFR. It was found that CST decreases with increase between the circles for $15.1 \mathrm{~mm}$ and 21.1 $\mathrm{mm}$ external diameter cylinder. The change in the internal diameters of cylinders $14.5 \mathrm{~mm}$ and $20 \mathrm{~mm}$ reduced the slope of the graphs showing consistent increase in flow rate with increase in the cylinder diameter.

\section{Conclusion}

This study modeled the relationship between Sludge Filtration Resistance (SFR) and Capillary Suction Time (CST) using the data generated from different concentrations of $\mathrm{CaCl}_{2}$ for SFR and CST empirically using the Equation proposed 


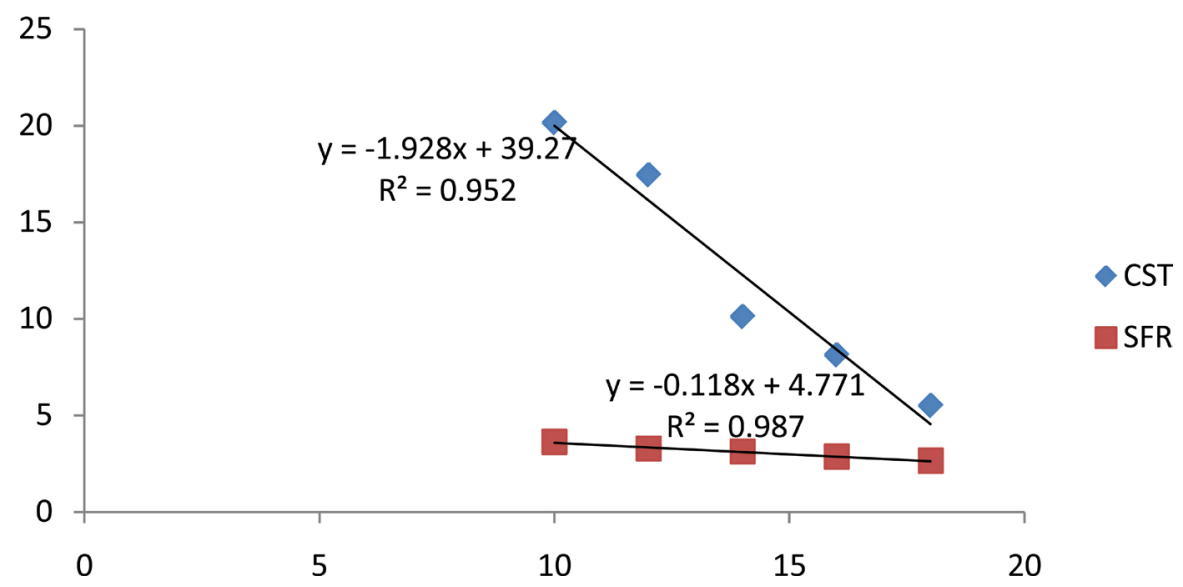

Figure 3. Plot of CST with SFR versus concentration of $\mathrm{CaCl}_{2}$ for $20 \mathrm{~mm}$ internal cylinder.

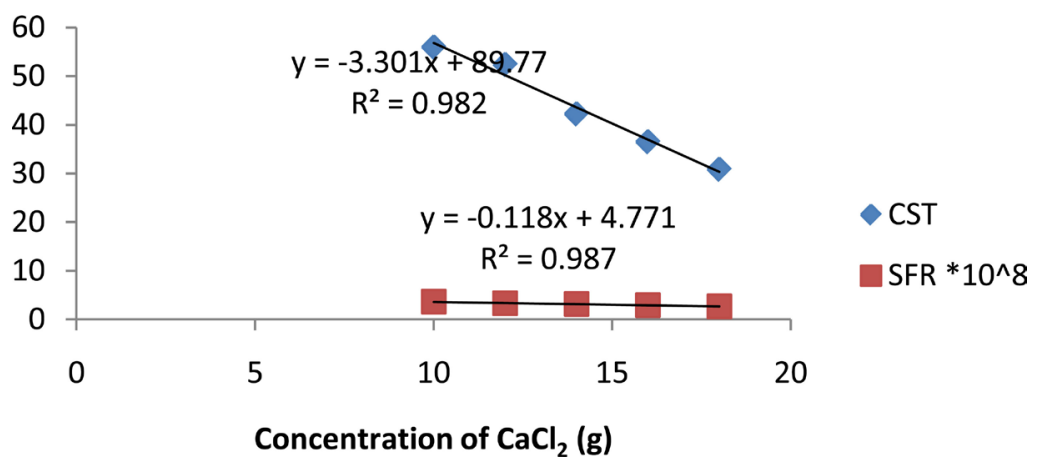

Figure 4. Plot of CST with SFR versus concentration of $\mathrm{CaCl}_{2}$ for $14.5 \mathrm{~mm}$ internal cylinder.

by [27]. The main purpose of conducting CST and SRF tests at wastewater treatment plants is to save operating costs by evaluating the optimal dose of the sludge conditioner, known as the dose of coagulant that yields the minimal capillary suction time or resistance to filtration. It was found that Figure $1 \&$ Figure 2 gave a linear relationship, showing a relatively good correlation for CST. Figure 3 \& Figure 4 showed that the values of CST decreased with increasing $\mathrm{CaCl}_{2}$ concentration, and a good dewaterability could be obtained at the $\mathrm{CaCl}_{2}$ dosage of $18 \mathrm{~g}$ with the corresponding CST of $5.52 \mathrm{~s}$ for $20 \mathrm{~mm}$ internal cylinder and $30.84 \mathrm{~s}$ for $14.5 \mathrm{~mm}$ internal cylinder. The results of SFR tests shown in Figure 3 \& Figure 4 decreased with an increase in $\mathrm{CaCl}_{2}$ dosage. The optimal $\mathrm{CaCl}_{2}$ dosage was $18 \mathrm{~g}$ and the corresponding SFR was $2.65 \times 10^{8} \mathrm{~N} \cdot \mathrm{s} / \mathrm{m}^{5}$. The results of this study for CST recommend larger diameter cylinder to be used to test heavy sludge because the larger cylinder significantly reduces the variability and the time taken to conduct the CST tests.

\section{References}

[1] Scholz, M. (2005) Review of Recent Trends in Capillary Suction Time CST Dewaterability Testing Research. Industrial and Engineering Chemistry Research, 44, 8157-8163. https://doi.org/10.1021/ie058011u 
[2] Bürger, R., Concha, F. and Karlsen, K.H. (2001) Phenomenological Model of Filtration Processes: 1. Cake Formation and Expression. Chemical Engineering Science, 56, 4537-4553. https://doi.org/10.1016/S0009-2509(01)00115-4

[3] Mowla, D., Tran, H.N. and Allen, D.G. (2013) A Review of the Properties of Biosludge and Its Relevance to Enhanced Dewatering Processes. Biomass and Bioenergy, 58, 365-378. https://doi.org/10.1016/j.biombioe.2013.09.002

[4] Gale, R.S. and Baskerville, R.C. (1967) Capillary Suction Method for Determination of the Filtration Properties of a Solid/Liquid Suspension. Chemistry and Industry, 9 , 355-356.

[5] Yukseler, H., Tosun, I. and Yetis, U. (2007) A New Approach in Assessing Slurry Filterability. Journal of Membrane Science, 303, 72-79.

https://doi.org/10.1016/j.memsci.2007.06.053

[6] Guan, J., Amal, R. and Waite, T.D. (2003) Effect of Floc Size and Structure on Biosolid Capillary Suction Time. Water Science and Technology: A Journal of the International Association on Water Pollution Research, 47, 255-260.

[7] Sawalha, O, and Scholz, M. (2007) Assessment of Capillary Suction Time (CST) Test Methodologies. Environmental Technology, 28, 1377-1386.

https://doi.org/10.1080/09593332808618898

[8] Bockstal, F., Fourarge, J.H. and Rahier, G. (1985) Constant Pressure Cake Filtration with Simultaneous Sedimentation. Filtration and Separation, 22, 255.

[9] Christiansen, G.L. and Dick, R.I. (1985) Specific Resistance Measurements: Non Parabolic Data. Journal of Environmental Engineering, 111, 243-257. https://doi.org/10.1061/(ASCE)0733-9372(1985)111:3(243)

[10] Leu, W.F. (1981) Cake Filtration. Ph.D. Dissertation, University of Houston, Houston, Texas.

[11] Lai, C.K., Chen, G. and Lo, M.C. (2004) Salinity Effect on Freeze/Thaw Conditioning of Activated Sludge with and without Chemical Addition. Separation and Purification Technology, 34, 155-164. https://doi.org/10.1016/S1383-5866(03)00189-8

[12] Ryan, T.P. (2007) Modern Engineering Statistics. Wiley-Interscience, Hoboken.

[13] Meeten, G.H. and Smeulders, J.B.A.F. (1995) Interpretation of Filterability Measured by the Capillary Suction Time Method. Chemical Engineering Science, 50, 1273-1279. https://doi.org/10.1016/0009-2509(95)98840-B

[14] Sawalha, O. (2010) CST: Developments in Testing Methodology and Reliability of Results. PhD Thesis.

[15] Saveyn, H. (2005) Modelling and Optimization of Sludge Conditioning and Electric Field Assisted Dewatering. PhD Thesis.

[16] Dereli, R.K., Grelot, A., Heffernan, B., van der Zee, F.P. and van Lier, J.B. (2014) Implications of Changes in Solids Retention Time on Long Term Evolution of Sludge Filterability in Anaerobic Membrane Bioreactors Treating High Strength Industrial Wastewater. Water Research, 59, 11-22. https://doi.org/10.1016/j.watres.2014.03.073

[17] Dereli, R.K., Heffernan, B., Grelot, A., van der Zee, F.P. and van Lier, J.B. (2015) Influence of High Lipid Containing Wastewater on Filtration Performance and Fouling in An MBRs Operated at Different Sludge Retention Times. Separation and Purification Technology, 139, 43-52. https://doi.org/10.1016/j.seppur.2014.10.029

[18] Lee, D.J. and Hsu, Y.H. (1994a) Use of Capillary Suction Apparatus for Estimating the Averaged Specific Resistance of Filtration Cake. Journal of Chemical Technology and Biotechnology, 59, 45-51. https://doi.org/10.1002/jctb.280590108 
[19] Herwijn, A.J., Heij, E.J.L., IJzermans, J.J., Coumans, W.J. and Kerkhof, P.J. (1995) Determination of Specific Cake Resistance with a New Capillary Suction Time Apparatus. Industrial and Engineering Chemistry Research, 34, 1310-1319. https://doi.org/10.1021/ie00043a036

[20] Ayol, A. and Dentel, S.K. (2005) Enzymatic Treatment Effects on Dewaterability of an Aerobically Digested Biosolids: Laboratory Characterizations of Drain Ability and Filterability. Process Biochemistry, 40, 2435-2442.

https://doi.org/10.1016/j.procbio.2004.09.024

[21] Teoh, S.K., Tan, R.B.H. and Tien, C. (2006) A New Procedure for Determining Specific Filter Cake Resistance from Filtration Data. Chemical Engineering Science, 61, 4957-4965. https://doi.org/10.1016/j.ces.2006.03.048

[22] Smollen, M. (1986) Dewaterability of Municipal Sludges 1: A Comparative Study of Specific Resistance to Filtration and Capillary Suction Time as Dewaterability Parameters. Water $S A, 12,277-132$.

[23] Smollen, M. (1986) Dewaterability of Municipal Sludges 2: Sludge Characterization and Behaviour in Terms of SRF and CST Parameters. Water SA, 12, 133-138.

[24] Zhao, Y.Q., Papavasilopoulos, E.N., Bache, D.H. and Mackinnon, P.A. (2002) Polymer Conditioning of Alum Sludge and Discrepancies between Estimates of the Optimum Dosage. Water Science and Technology, 46, 115-121.

[25] Emir, E.Ü. (2002) The Role of Dewaterability Measures on the Liquid-Solid Separation of Biological Sludges: Compatibility as a New Measure of Sludge Dewaterability Bogazici University. Institute of Environmental Sciences, Filters and Filtration, 166 p.

[26] Chia-Hung, H. and Kung-Cheh, L. (2003) Assessment of Sludge Dewaterability using Rheological Properties. Journal of the Chinese Institute of Engineers, 26, 221-226. https://doi.org/10.1080/02533839.2003.9670772

[27] Christensen, J.R., Sorensen, P.B., Christensen, G.L. and Hansen, J.A. (1993) Mechanisms for Overdosing in Sludge Conditioning. Journal of Environmental Engineering, 119, 158-171. https://doi.org/10.1061/(ASCE)0733-9372(1993)119:1(159)

[28] Ma, W., Zhao, Y.Q. and Kerney, P. (2007) A Study of Dual Polymer Conditioning of Aluminium Based Drinking Water Treatment Residual. Journal of Environmental Science and Heath, Part A, 42, 961-968. https://doi.org/10.1061/(ASCE)0733-9372(1993)119:1(159)

[29] Peng, G., Ye, F. and Li, Y. (2011) Comparative Investigation of Parameters for Determining the Dewaterability of Activated Sludge. Water Environment Research, 83, 667-671.

[30] Ademiluyi, J.O. and Onah, C. (2011) Study on Sludge Dewaterability using the Concept of Capillary Suction Time. Research Thesis Unpublished. 